\title{
Laparoscopic intragastric approach for gastroesophageal leiomyoma and cancer
}

\author{
M. Blair Marshall, MD, ${ }^{\mathrm{a}}$ and Nadime G. Haddad, MD, ${ }^{\mathrm{b}}$ Washington, DC
}

Laparoscopic intragastric surgery was first described by Ohashi. ${ }^{1}$ We report our technique in the management of gastroesophageal junction (GEJ) leiomyoma and superficial cancers. This technique allows for excellent exposure of the pathology of the GEJ with minimal dissection of the stomach or disruption of the vagi.

For leiomyoma, all patients undergo endoscopic biopsy to rule out a gastrointestinal stromal tumor before local excision.

\section{INSTRUMENTS/EQUIPMENT}

For this technique, we used four $5 \mathrm{~mm}$ Kii and one 10/12 Kii balloon anchored ports (Applied Medical, Rancho Santa Margarita, Calif). We also used a PENTAX EG esophagoscope (PENTAX Medical, Cedex, France), a Captivator Single-Use Snare (Boston Scientific, Natick, Mass), CODA balloons (Cook Incorporated, Bloomington, Ind), and the appropriate laparoscopic instruments.

From the Divisions of Thoracic Surgery ${ }^{\mathrm{a}}$ and Gastroenterology, ${ }^{\mathrm{b}}$ MedStar Georgetown University Hospital, Washington, DC.

Disclosures: M. Blair Marshall reports consulting fees from Ethicon. All other authors have nothing to report with regard to commercial support.

Received for publication Aug 21, 2014; revisions received Sept 4, 2014; accepted for publication Dec 14, 2014; available ahead of print Jan 23, 2015.

Address for reprints: M. Blair Marshall, MD, Division of Thoracic Surgery, Georgetown University, 3800 Reservoir Rd, Washington, DC 20007 (E-mail: mbm5@gunet.georgetown.edu).

J Thorac Cardiovasc Surg 2015;149:1210-2

$0022-5223 / \$ 36.00$

Copyright $(2015$ by The American Association for Thoracic Surgery

http://dx.doi.org/10.1016/j.jtcvs.2014.12.030

\section{TECHNIQUE}

The patient is positioned supine the split-leg positioner. Esophagoscopy is performed, and after thorough inspection, the scope is left in place following evacuation of air from the stomach.

A $5 \mathrm{~mm}$ incision is made in the umbilicus, a port is placed, and the abdomen is insufflated with carbon dioxide. The stomach is then insufflated using the esophagoscope. It is critical to release the insufflation pressure within the abdominal cavity, otherwise the stomach will not inflate.

The location of the stomach and planned port placement on the abdominal wall for subsequent placement through the gastric wall is identified. Three additional $5 \mathrm{~mm}$ ports are placed through the abdominal wall with the ultimate intention of placing them through the gastric wall (Figure 1, A).

The intragastric ports should be positioned within the proximal stomach to facilitate work at the GEJ. Tacking sutures are placed in the gastric wall, and a gastrotomy is made with cautery. The ports are then placed into the insufflated stomach. The distal balloon on the port is insufflated and the port brought against the abdominal wall (Figure 1,B) The instruments are now placed into the stomach through these ports.

A guidewire is placed through the esophagoscope into the duodenum and the CODA balloon threaded over this into the duodenum. The balloon is insufflated to obstruct the duodenum and prevent air entry into the small bowel.

For leiomyoma, a stitch is placed through the lesion and it is retracted into the gastric lumen (Figure 2, A). The appropriate $5 \mathrm{~mm}$ port, as determined by the anticipated trajectory of the endoscopic stapler, can be switched out
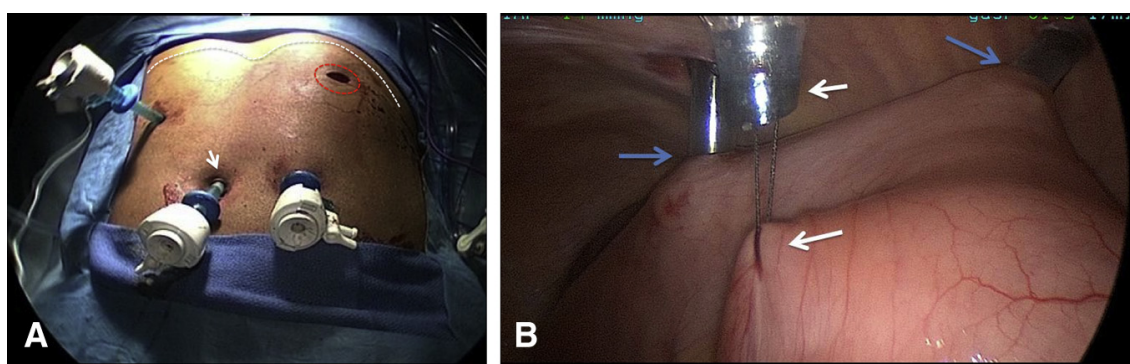

FIGURE 1. A, Intraoperative photograph showing port placement for resection of a gastroesophageal junction leiomyoma. The umbilical port is marked with an arrow and the $10 \mathrm{~mm}$ port is circled. The costal margin is outlined with a dotted line. B, Laparoscopic view of a stomach wall being tented up with the intragastric balloon anchored ports (blue arrows) and third port in the process of being advanced into gastric lumen with silk suture tacking the gastric wall (white arrows). 

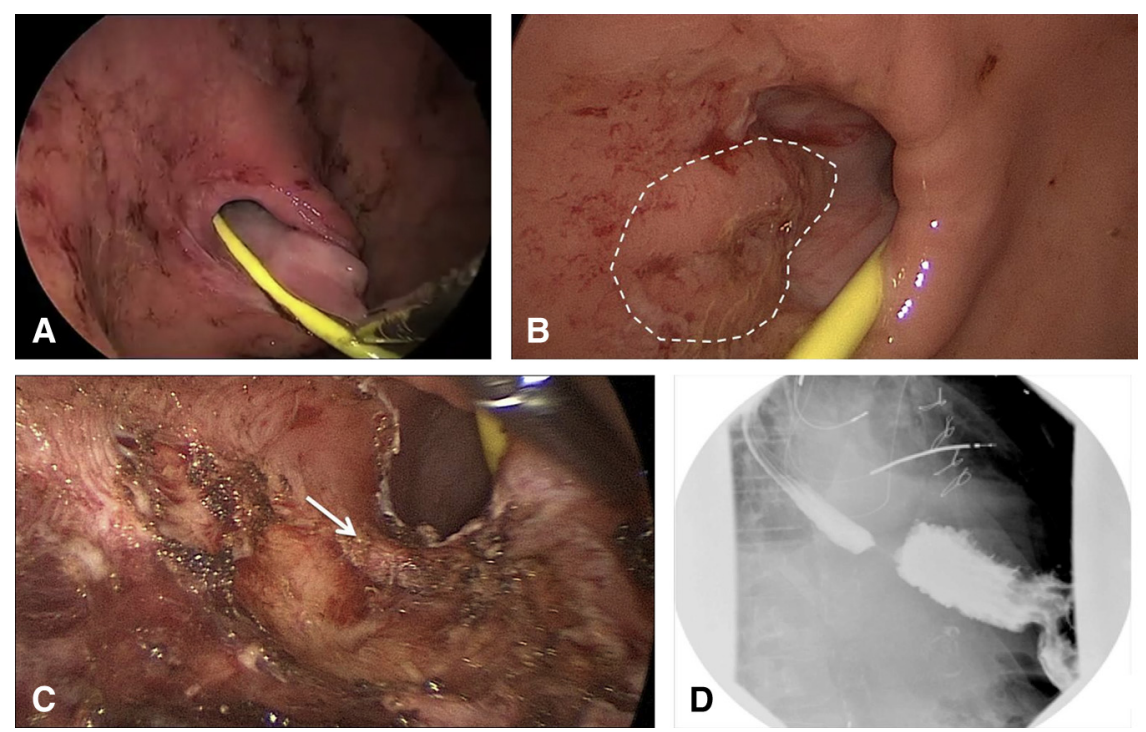

FIGURE 2. A, Leiomyoma of gastroesophageal junction (GEJ) being delivered into the gastric lumen. The yellow catheter of the balloon situated in the duodenum is seen coursing through the GEJ. B, GEJ tumor coursing between the distal esophagus and stomach (dotted line). The z-line can be appreciated by the change in color of the mucosa of the esophagus and stomach. C, Completed full thickness resection of the cancer. The arrow points to the muscular layer of the esophagus. Yellow fat can be seen at the base of the resection. D, Postoperative esophagram demonstrating passage of contrast from the esophagus to the stomach following resection of GEJ cancer.

to the $10 / 12 \mathrm{~mm}$ port and the stapler fired across the base. We use a $45 \mathrm{~mm}$ articulating linear cutting stapler with a final staple height of $2.00 \mathrm{~mm}$. For cancers, a full thickness excision can be performed with cautery (Figure 2, $B$ and $C$ ). When closing the remaining defect, the orientation of the incision is changed to avoid narrowing the lumen at the GEJ. Tacking the balloon catheter to the lateral gastric wall will minimize interference during suture closure. Once resected, large lesions can be snared with the esophagoscope and delivered through the mouth. When the intragastric portion of the procedure is completed, if there are concerns, a gastric tube can be placed through 1 of the ports to drain the stomach before an esophagram (Figure 2,D). The remainder of ports are removed and the gastrotomies are closed. The trocars are then removed from the abdomen and abdominal incisions closed. For leiomyomas that have been resected with a linear stapler, we obtain an esophagram on the first postoperative day before starting a diet. For lesions resected with primary suture closure, we have waited a few days before obtaining the esophagram.

\section{DISCUSSION}

Although similar techniques have been previously reported for gastric cancers and leiomyomas, ${ }^{2,3}$ they have not been used in patients with distal esophageal lesions spanning the GEJ. From our experience in resecting 3 leiomyoma and 2 cancers, we have learned several points. An individual patient's gastric anatomy will dictate ideal port placement following insufflation. The location of the leiomyoma will determine which port is optimal for the stapler trajectory. If one considered the orientation of the GEJ like a clock, lesions in the 6 o'clock region worked with a stapler fired from the right side of the patient where as at 3 o'clock, a stapler fired from the left upper quadrant seemed most ideal. It is critical to deliver the leiomyoma fully into the gastric lumen before firing the stapler. For leiomyoma, thorascopic enucleation is technically easy with this approach; however, for very distal esophageal or proximal gastric lesions enucleation is more challenging given the location. We have aborted this technique for these cases. Large leiomyoma of the GEJ with the bulk of the tumor on the esophageal side are still best approached with a standard thorascopic enucleation.

Although superficial mucosal resections may be technically possible in patients with cancer, after endoscopic mucosal resection this is no longer possible. Because of the excellent view into the distal esophagus, this technique may have potential in resecting early stage esophageal lesions. Likely, the advantages of the robotic approach with articulating arms and binocular vision would convey significant advantages with this approach in performing full thickness resections up into the esophagus. Long-term oncologic outcomes remain to be seen.

\section{References}

1. Ohashi S. Laparoscopic intraluminal (intragastric) surgery for early gastric cancer-a new concept in laparoscopic surgery. Surg Endosc. 1995;9: $169-71$. 
2. Tagaya N, Mikami H, Kogure H, Kubota K, Hosoya Y, Nagai H. Laparoscopic intragastric stapled resection of gastric submucosal tumors located near the esophagogastric junction. Surg Endosc. 2002;16:177-9.
3. Conrad C, Nedelcu M, Ogiso S, Aloia TA, Vauthey JN, Gayet B. Laparoscopic intragastric surgery for early gastric cancer and gastrointestinal stromal tumors. Ann Surg Oncol. 2014;21:2620.

\title{
Complications of intrathoracic lines placed during cardiac surgery
}

\author{
Himanshu Pratap, MS, MBBS, ${ }^{a}$ Johnny Millar, MBChB, PhD, ${ }^{\mathrm{b}}$ Warwick Butt, MBBS, ${ }^{\mathrm{b}, \mathrm{c}, \mathrm{d}}$ and \\ Yves d'Udekem, MD, PhD, ${ }^{\mathrm{a}, \mathrm{b}, \mathrm{d}}$ Melbourne, Victoria, Australia
}

See related commentary on page 1214 .

Intracardiac catheters are frequently used in pediatric patients for monitoring intracardiac pressures and to provide vascular access. Data are scarce on the incidence of complications related to use of such catheters. ${ }^{1-3}$

Since January 2005 , all health data for patients transiting the intensive care unit of the Royal Children's Hospital (Melbourne, Australia) have been entered into our database

From the Department of Cardiac Surgery, ${ }^{\text {a }}$ The Royal Children's Hospital, Melbourne; Department of Pediatrics, ${ }^{\mathrm{b}}$ University of Melbourne, Melbourne; Paediatric Intensive Care Unit, ${ }^{\mathrm{c}}$ The Royal Children's Hospital, Melbourne; and Murdoch Children's Research Institute, ${ }^{\mathrm{d}}$ Melbourne, Victoria, Australia.

This research project was supported by the Victorian Government's Operational Infrastructure Support Program.

Disclosures: Yves d'Udekem is a Career Development Fellow of The National Heart Foundation of Australia (CR 10M 5339) and National Health and Medical Research Council Clinician Practitioner Fellow (1082186). All other authors have nothing to disclose with regard to commercial support.

Received for publication July 23, 2014; revisions received Nov 3, 2014; accepted for publication Nov 28, 2014; available ahead of print Jan 13, 2015.

Address for reprints: Yves d'Udekem, MD, PhD, Department of Cardiac Surgery, Royal Children's Hospital, Flemington Rd, Parkville, Melbourne, Victoria 3052, Australia (E-mail: yves.dudekem@rch.org.au).

J Thorac Cardiovasc Surg 2015;149:1212-3

$0022-5223 / \$ 36.00$

Copyright (C) 2015 by The American Association for Thoracic Surgery

http://dx.doi.org/10.1016/j.jtcvs.2014.11.082 for that unit, with 1 entry being devoted to the following catheter line-related complications: migration (inadvertent extrusion of the line outside its desired location) or premature removal (earlier than planned removal); bleeding after line removal (unexpected drain output or substantial pericardial collection after planned line removal); line occlusion (absent waveform tracings); thrombosis (echocardiographic demonstration of thrombus in the cardiac chamber containing the line); and failed removal. The files of all patients recorded as having a line-related complication were reviewed.

Left atrial (LA) and right atrial (RA) lines were inserted through their respective appendages and secured with 2 purse-strings of Prolene 6-0 (polypropylene) (Covidien, Mansfield, Mass) placed around the entry point of the line, with the addition of a silk suture per surgeon preference. To avoid migration of the RA lines, 1 surgeon additionally secured the line by looping the ends of the purse-string suture along the extracardiac portion of the line and tying it off near the entry point. The other 2 surgeons left a long loose segment of lines between the entry in the chest and the insertion in the RA appendage (Figure 1).

Right atrial lines were pediatric multilumen central venous catheters (Arrow International, Inc, Reading, Pa); LA lines were polyurethane umbilical vessel catheters (Tyco Healthcare Group LP, Mansfield, Mass). Pressure catheter placement sets (Medtronic, Inc, Minneapolis, Minn) were used as

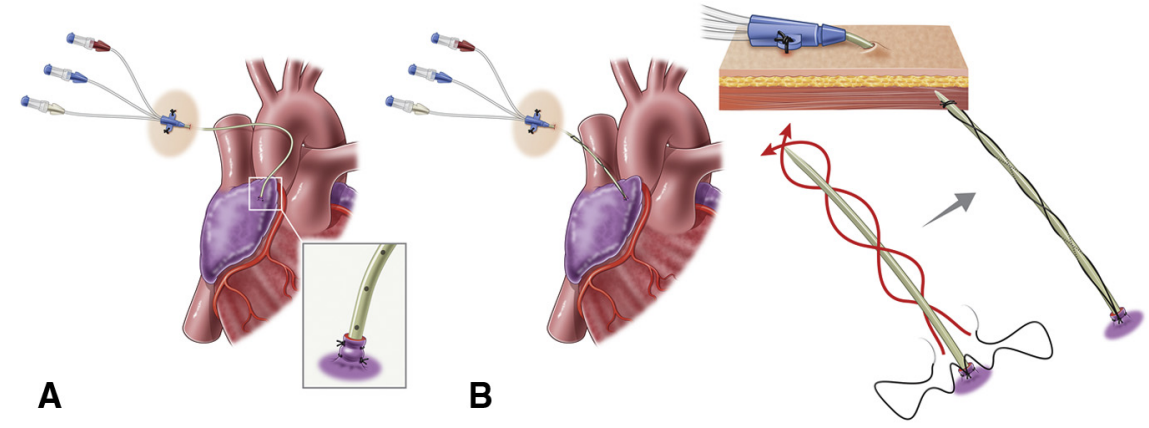

FIGURE 1. Techniques of insertion of a direct right atrial line to prevent the line from being pulled off by lung inflation. A, A long loop is left on the line before the entry point into the right atrium. B, A 7-0 polydioxanone suture is secured between the entry point of the line into the skin and its entry point into the right atrium. 